\title{
Energy-Exergy Analysis and Carbon (IV) Oxide Emission of an Aluminium Extrusion Plant in Nigeria
}

\author{
Mufutau Adekojo Waheed1, Peter Olaitan Aiyedun1, Wasiu Oyediran Adedeji ${ }^{*}$, \\ Adekunle Adedapo Obisanya ${ }^{3}$, Semiu Taiwo Amosun ${ }^{2}$, Adeniyi Oluwole Adesina ${ }^{2}$ \\ ${ }^{1}$ Department of Mechanical Engineering, Federal University of Technology, Abeokuta, Nigeria \\ ${ }^{2}$ Department of Mechanical Engineering, Yaba College of Technology, Lagos, Nigeria \\ ${ }^{3}$ Department of Chemical Engineering, Yaba College of Technology, Lagos, Nigeria \\ Email: *diranadedeji@yahoo.com
}

How to cite this paper: Waheed, M.A., Aiyedun, P.O., Adedeji, W.O., Obisanya, A.A., Amosun, S.T. and Adesina, A.O. (2017) Energy-Exergy Analysis and Carbon (IV) Oxide Emission of an Aluminium Extrusion Plant in Nigeria. Engineering, 9, 1048-1059. https://doi.org/10.4236/eng.2017.912062

Received: November 21, 2017

Accepted: December 26, 2017

Published: December 29, 2017

Copyright $\odot 2017$ by authors and Scientific Research Publishing Inc. This work is licensed under the Creative Commons Attribution International License (CC BY 4.0).

http://creativecommons.org/licenses/by/4.0/

\begin{abstract}
Energy security, cost of production and environmental constraints have necessitated the need for proper energy utilisation in the manufacturing industries. This work analysed energy and production data from an aluminium extrusion plant in Lagos, Nigeria for energy efficiency, exergy efficiency (or process efficiency), energy cost per unit of production, $\mathrm{CO}_{2}$ emission and pollution rate index. The input-output energy analysis method was used to estimate the embodied energy intensity. The pollution rate, energetic and exergetic efficiencies were estimated from the exergy analysis. The $\mathrm{CO}_{2}$ emission was estimated from IPCC guideline on greenhouse inventories and the energy cost of unit produce was estimated from energy cost accounting method. The five-year average thermal and electrical utilisation ratio was $45 / 55$, which deviated from the 70:30 of the global best practices. The embodied energy intensity for the five years' ranges between $2.31-162.3 \mathrm{GJ} / \mathrm{t}$ which is in excess of the recommended range of $(2.9-3.2 \mathrm{GJ} / \mathrm{t})$. The mean energy efficiency for the five year was $79.4 \%$ and the mean exergetic efficiency was $57.8 \%$ indicating that production was well managed $(>50 \%)$ with energy wastages very high in boiler energy conversion. The total energy used was $16 \mathrm{MJ}$ and $\mathrm{CO}_{2}$ emitted is $1.01 \times 10^{11} \mathrm{~g}$ during the study period. The average pollution rate index for the plant was 0.8695 indicating that the plant is negatively impacting the environment due to technological limitation of the energy conversion process employed in the manufacturing plant. The study reveals a distortion of the recommended best practice in energy balance ratio which accounted for the high average cost of production ( $4418.3 / t$ ); process efficiency was generally low thereby negatively affecting industrial output for the company.
\end{abstract}




\section{Keywords}

Exergy, Energy, Carbon (IV) Oxide, Emission, Pollution

\section{Introduction}

The integral driver of national economic development in the $21^{\text {st }}$ century is energy production. Throughout history, energy has played a leading role in society development. Without the energy to meet the ever-increasing world population food and material demand, the world would have been grind to a halt. Presently, energy and energy related services are the core values of the world leading companies. Since the deregulation of the major energy market, the energy industry has witnessed one of the fiercest competitions as energy producers strive to drive cost saving through their business and to secure increasing share of the global market. The industrial sectors and other companies are faced with core issues such as energy security, political decision, environmental pressure, legal and technological challenges. Operational issues like finance, human resources management, marketing, information technology, production and corporate governance also play significant roles in the performance of these industries [1]. This importance in industrial energy usage has attracted serious attention as evident in the work of [2] [3] [4] and [5]

In the literature, the quantification of the inherent potential of any energy material quantity to cause environmental change at a given set of conditions has been discussed in several ways. The most common one of those definitions is exergy. The non-inclusion of irreversibility made the first law of thermodynamics not suitable for energy efficiency evaluation. Exergy efficiency represents the second law efficiency which is the ratio of the exergy of product to the exergy of all input streams. Typically, the exergy efficiencies are lower than the energy efficiencies because of the input exergy destruction due to irreversibility. Exergy analysis is an effective tool that combines the second law of thermodynamics with law of conservation of mass and energy for design and analysis of energy systems, improving efficiency, revealing possibility of improved systems, addressing environmental impact and identifying sustainability [6].

The use of exergy analysis to assess the energy utilization of a system (Country/ factory) was performed by Reistad [7], who applied it to United States of America. Since then, countries like Canada [8], Japan, Finland, Sweden [9] [10] [11], and Turkey [12] [13] have also been analysed using the modified version of the technique. Exergy analysis has also been applied to aluminium recovery processes [14], die casting [15] and aluminium holding furnace [16].

Energy consumption of South Africa industrial sector has been analysed using energy-exergy analysis by Oladiran and Mayer [17]. In Nigeria, Diji [18] analysed the energy-exergy utilization as well as the $\mathrm{CO}_{2}$ emission patterns in cement manufacturing industries. The application of exergy analysis to various local indus- 
tries has been well documented in the literature [19] [20] [21] [22] [23] but none work has been done in aluminium industry.

In Nigalex Aluminium Extrusion Company, the Aluminium extrusions are manufactured by extruding or forcing heated aluminium billets at about $500^{\circ} \mathrm{C}$ through a steel die. The emerged extruded section is then cooled and sized to desired length. The inherent mechanical properties of materials are then optimised using heat treatment. Design time, improve tolerance, and close accurate control is achieved by computer aided design. For protection and improved finish appearances, natural silver or colour anodized film, plus range of colours in polyester powder coating are used. Al-Mg-Si alloys of 6060, 6063 and 6082 gives the best combination of medium strength (190 - $310 \mathrm{MPa}$ ), good surface finish and corrosion resistance, with excellent anodising properties.

Product units from the plant include projected window system, door system (AS46), partitioning system, Special profiles, Real wood system, curtain wall CW54 (with fixed glass), swing door system, fixed louvre, Railings, Casement (window \& fixed glass), Casement (window \& fixed glass)-CW42 and sliding window system (both CEGO1 \& CEGO2).

In this study, exergy analysis is used to estimate the efficiency of energy conversion in the aluminium extrusion process and the total pollution rate of the process.

\section{Methodology}

Energy and production data collected from the aluminium extrusion plant were analysed for the embodied energy intensity, efficiency of energy use, pollution rate, $\mathrm{CO}_{2}$ emission and energy cost of production. The primary data collected were:

1) Fuel consumption (diesel) for energy value estimation.

2) Main supply data as electricity bills (KWh).

3) Volume of production output (in tonnes).

The general outlay of the research layout is shown in Figure 1.

Net Energy Analysis

The embodied energy intensity or the primary energy requirement for the production of one unit of a product is estimated using the Net Energy [Input-Output Energy Analysis (IOEA)] method. The embodied energy intensity is defined as [24]:

$$
\mathrm{EEI}=\frac{\mathrm{TEUS}}{\mathrm{TQPS}}
$$

TEUS is the total energy used in the sector and TQPS is the total quantity of product in the sector.

In this method, the inputs are arranged in a matrix form, normalized to one unit. This matrix is one way to represent the technologies for all goods and services in the industries. The energy balance of a particular product is given by:

$$
E=e(I-A)^{-1}
$$




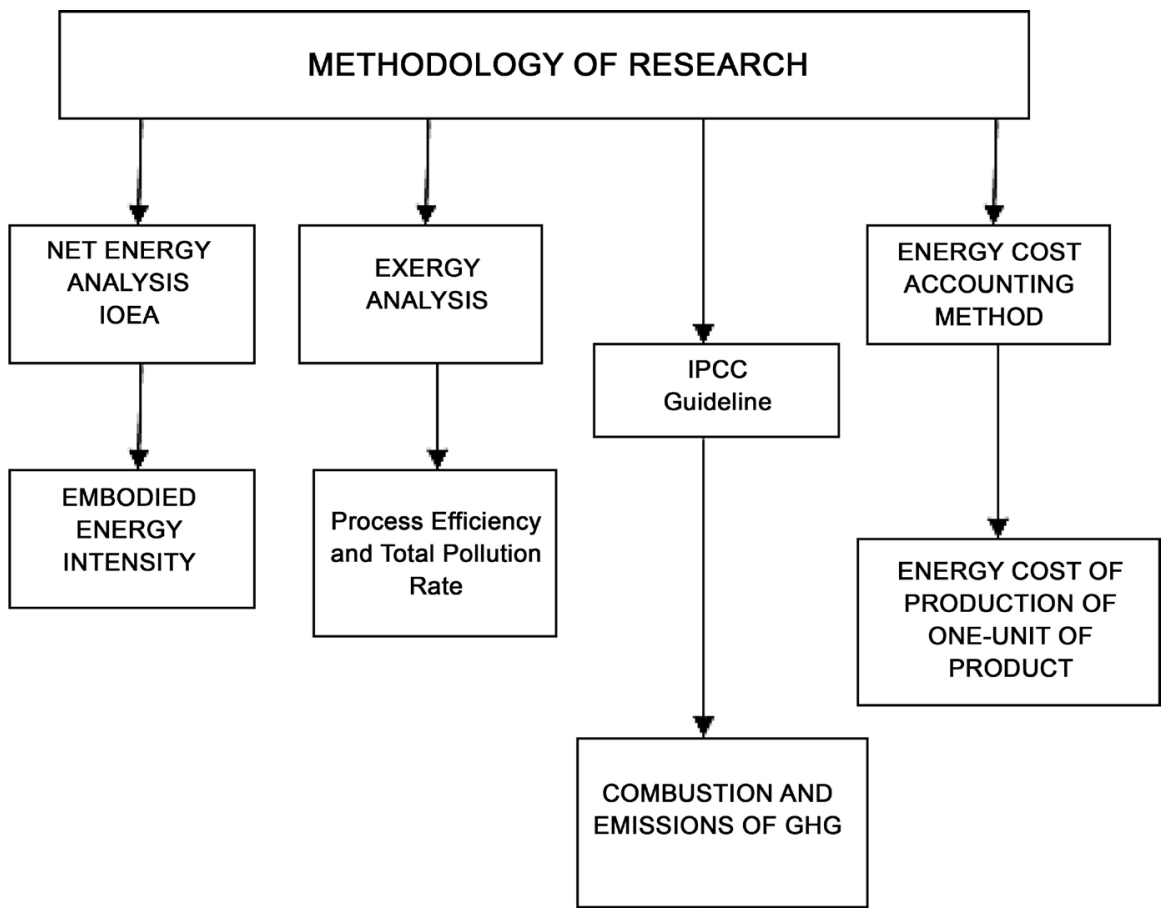

Figure 1. The outline of the research methodology.

where $e$ is a unit vector, which shows the energy sector row of $(I-A)^{-1}$ as the energy intensities. $A$ is a $N \times N$ matrix that provides the linear representation of goods and service production technologies. For a particular product $N$, the production technology is represented by a vector $A_{n}$, where a typical element $A_{i n}$ represents the amount of product i needed directly to produce a unit of product n.

$$
I=A \hat{X}
$$

where $\hat{X}$ is the diagonal matrix whose elements represents the total output from each sector.

Exergy Analysis

Exergy is that part of energy that is convertible into all other forms of energy. The expressions used in the exergy analysis are expressed below (Table 1).

The expressions for energy efficiency $(\eta)$ and exergy efficiency $(\psi)$ for the main types of processes in this work are as follows:

$$
\eta=\frac{\text { Energy in product }}{\text { Total energy input }}, \psi=\frac{\text { Exergy in product }}{\text { Total exergy input }}
$$

The particular efficiencies are listed in Table 2 [23].

\section{The Total Pollution Rate}

The index of measurement for pollution rate is given by [29]

$$
R_{\text {Poll }}=\frac{B_{\text {waste }}}{B_{\text {input }}}
$$

When $R_{\text {Poll }} \gg 1$ : Process is producing emission and wastes hazards to the environment. 
Table 1. Formulas for exergy analysis.

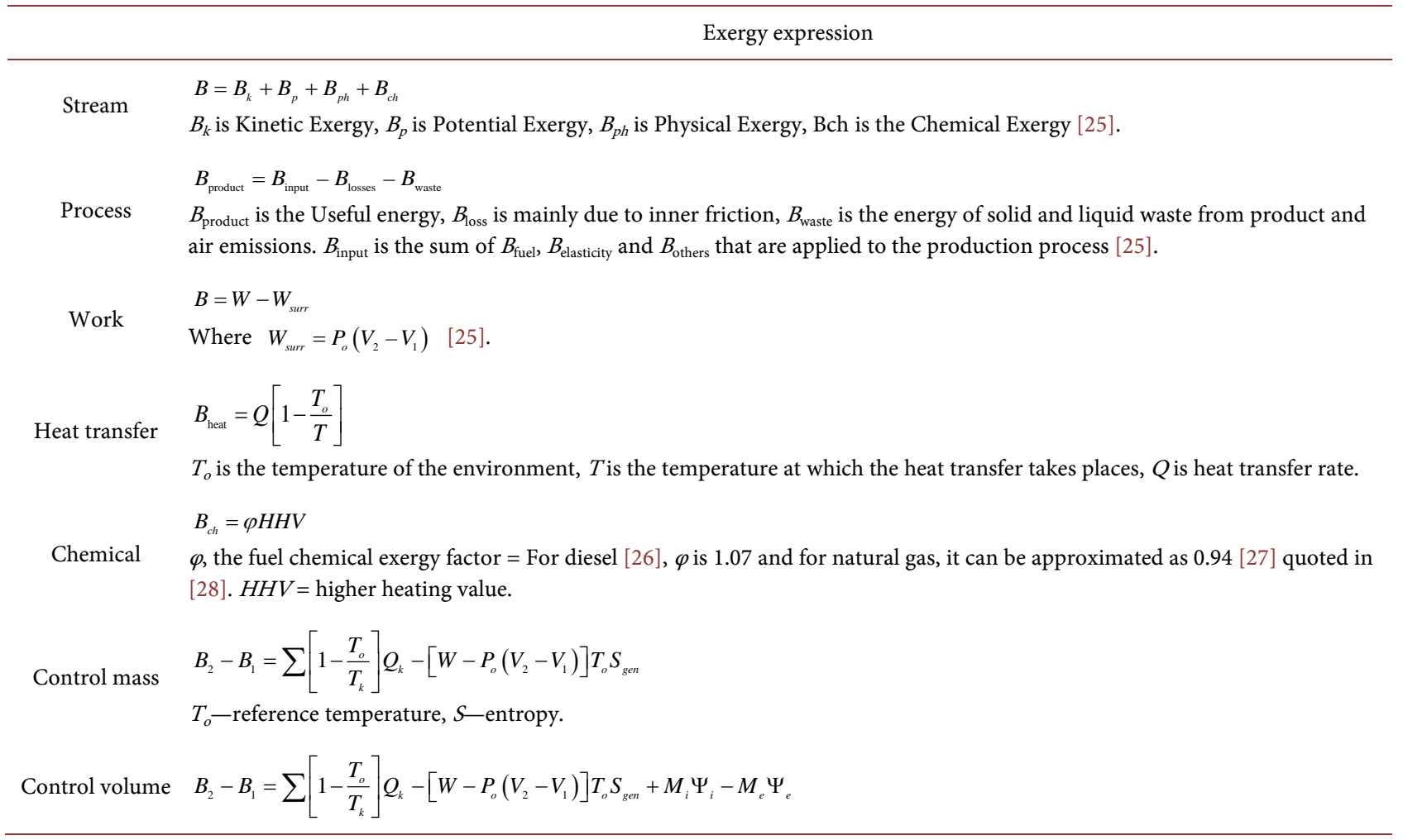

Table 2. Expressions for efficiency estimation.

\begin{tabular}{|c|c|c|c|}
\hline Units & Energetic Efficiency & Exergetic Efficiency & References \\
\hline Boiler & $\eta_{b}=\frac{Q_{o, b}}{Q_{i, b}}$ & $\psi_{b}=\frac{X_{b}}{\varphi Q_{i, b}}$ & \\
\hline Generator & $\eta_{g}=\frac{W_{e, g}}{Q_{g}}$ & $\eta_{g}=\frac{Q_{e, g}}{\varphi Q_{g}}$ & \\
\hline Electrical Energy & $\eta_{e}=\frac{W_{e, m}+\eta_{g} Q_{g}}{W_{e, m}+Q_{g}}$ & $\psi_{e}=\frac{W_{e, m}+\psi_{g} \varphi Q_{g}}{W_{e, m}+\varphi Q_{g}}$ & \\
\hline Total & $\eta_{e}=\frac{W_{e, m}+\eta_{g} Q_{g}+\eta_{b} Q_{i, b}}{W_{e, m}+Q_{g}+Q_{i, b}}$ & $\eta_{e}=\frac{W_{e, m}+\psi_{g} \varphi Q_{g}+\psi_{b} \varphi Q_{i, b}}{W_{e, m}+\varphi Q_{g}+\varphi Q_{i, b}}$ & \\
\hline \multicolumn{4}{|c|}{$\phi_{p}=\frac{D_{\text {product }}}{B_{\text {input }}}$ where $\phi_{p}$ is the } \\
\hline Exergy Losses (ANERGY) & & & \\
\hline
\end{tabular}

When $R_{\text {poll }}=0:$ Process is reversible and environmentally friendly.

When $0 \ll R_{\text {poll }} \ll 1$ : Impact based on techniques by limitation of the energy conversion process.

Carbon IV Oxide Emissions Estimation

The $\mathrm{CO}_{2}$ emission was estimated by the following six steps Intergovernmental Panel on Climate Change (IPCC), guidelines (reference approach) on Natural Green- 
house Gas inventories [30].

1) Estimation of fuel consumption in original unit.

2) Conversion to common energy unit.

3) Calculation of carbon content by multiplying with emission factor.

4) Calculation of carbon stored.

5) Correcting for unoxidised carbon.

6) Convert to $\mathrm{CO}_{2}$ emission.

\section{Economic Analysis of Energy Usage}

The Electricity tariff of $\$ 8.50$ for power consumption above 20 MVA between 2002 to 2009 [31] is taken to be an equivalent unit cost $C_{m}$. The expressions for other unit cost estimation [23] are presented in Table 3.

\section{Results and Discussion}

\section{Energy Consumption and Utilization Efficiency}

The source of energy at the Nigalex Aluminium Extrusion Plant, Oshodi, Lagos, Nigeria include diesel generators, diesel fuelled boilers (as thermal energy carriers) and PHCN as main electricity supply. As shown in Table 4 below, the major energy source for the operation of this industry is from diesel i.e. thermal: electrical.

The mean energy balance between diesel generators and main electricity supply for the five years (2008-2012) was 44/56, 46/54, 37/63, 51/49 and 48/52. The energy balance for year 2011 was the nearest to recommended 70/30 while year 2010

Table 3. Formulas for estimating unit cost.

\begin{tabular}{ccc}
\hline & Energy Cost & Exergy Cost \\
\hline Boiler & $C_{n, b}=\frac{c_{f}}{\eta_{g} H H V}$ & $C_{n x, b}=\frac{C_{f}}{\varphi_{g} \psi_{b} H H V}$ \\
Diesel Generator & $C_{n, g}=\frac{c_{f}}{\eta_{g} H H V}$ & $C_{n x, b}=\frac{C_{f}}{\varphi_{g} \psi_{g} H H V}$ \\
Mean Electricity Output & $\bar{C}_{n, e}=\frac{C_{m}+W_{e, m}+C_{n, g} x Q_{g}}{W_{e, m}+\eta_{g} Q_{g}}$ & $\bar{C}_{x, e}=\frac{C_{m}+W_{e, m}+C_{n, g} x \varphi Q_{g}}{W_{e, m}+\psi_{g} \varphi Q_{g}}$ \\
Overall Mean Energy Unit Cost & $\bar{C}_{n}=\frac{C_{m}+W_{e, m}+C_{n, g} x Q_{g}+C_{n, b} x Q_{i, b}}{W_{e, m}+\eta_{g} Q_{g}+\eta_{b} Q_{i, b}}$ & $\bar{C}_{x}=\frac{C_{m}+W_{e, m}+C_{n, g} x \varphi Q_{g}+C_{x, b} x \varphi Q_{i, b}}{W_{e, m}+\psi_{g} \varphi Q_{g}}$ \\
onerall mean energy unit cost $(\mathrm{N} / \mathrm{GJ}) \times$ embodied energy intensity $(\mathrm{GJ} /$ tonne $)$
\end{tabular}

$C=$ unit cost, $c=$ cost, $H H V=$ higher heating value, $g-$ generator, $b$-boiler, $f-$ fuel, $i-$ input, $e-$ output, $m-$ mean, $W$-work, $Q-$ heat energy, $\varphi-$ chemical exergy factor, $\eta$ - energy efficiency, $X$-exergy, $\psi$-exergy efficiency.

Table 4. Mean energy mix of the production processes.

\begin{tabular}{ccccccc}
\hline & $\mathbf{2 0 0 8}$ & $\mathbf{2 0 0 9}$ & $\mathbf{2 0 1 0}$ & $\mathbf{2 0 1 1}$ & $\mathbf{2 0 1 2}$ \\
\hline Mean Main Electricity Supply \% & 55.71 & 53.9 & 62.88 & 49.49 & 51.66 \\
Mean Diesel Generators \% & 44.27 & 46.09 & 37.11 & 50.50 & 48.33 \\
Mean Diesel Fuelled Boilers \% & 0.014 & 0.011 & 0.014 & 0.011 & 0.010 \\
\hline
\end{tabular}


was farthest from the recommended. For the five year, the mean energy balance was $45 / 55$, this was disproportionate to the main supply as opposed to $70 / 30 \mathrm{rec}$ ommended as best practices. The energy supply mix from the three sources (i.e. generator, boiler and main utility are shown in Figure 2.

\section{Exergy Analysis}

The exergy analysis reveals a $99.91 \%$ transformation of electrical energy to electrical Exergy, a 36.75\% transformation of boiler energy to boiler exergy and $99.90 \%$ for the total energy as shown in Figure 3. This means that the quality of the energy produced in boiler was very low that is, wastages were very high in boiler energy conversion.

The Figure 3 shows that high generator fuel consumption largely affects the total energy efficiency adversely and the better the energy mix, the higher the efficiencies.

The exergy values were all slightly below the energy values and graphically follow the same trend in the period under review as shown in Figure 4.

\section{Process Efficiency}

As shown in Table 5, the process efficiencies for the five years under review for this manufacturing organisation, were $61.34 \%$ for $2008,71.46 \%$ for $2009,32.4 \%$

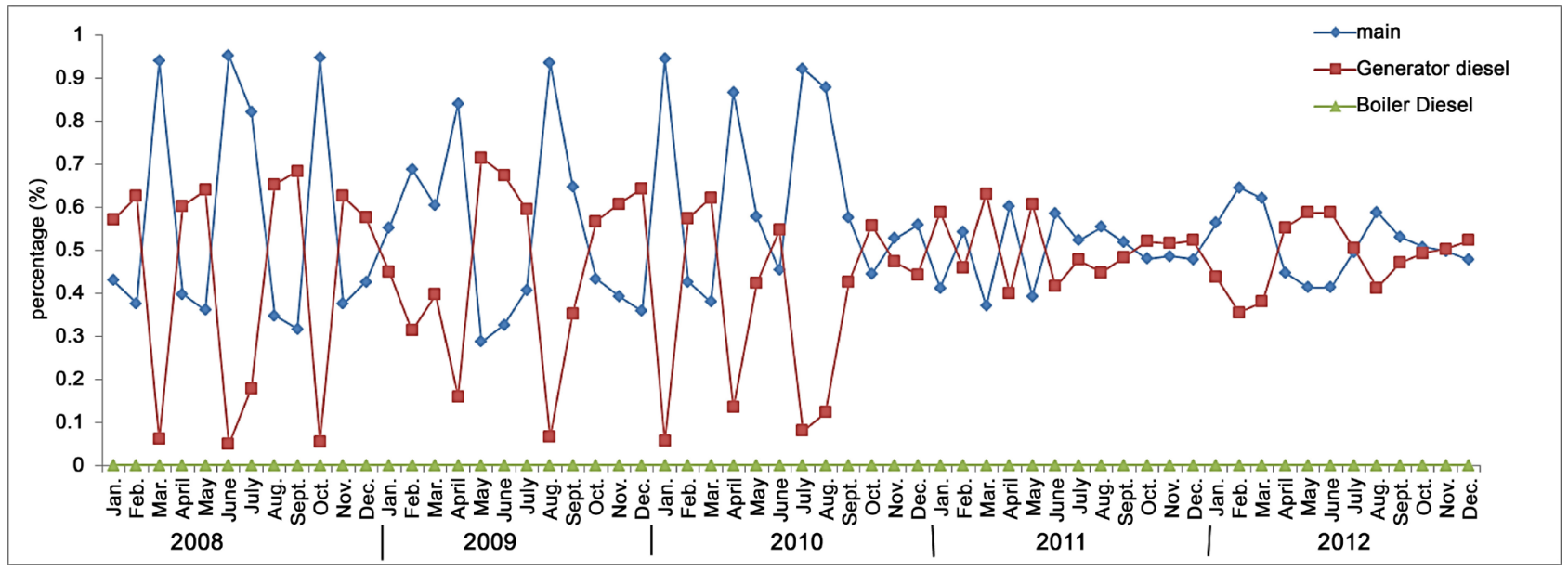

Figure 2. Energy mix for the five years' interval.

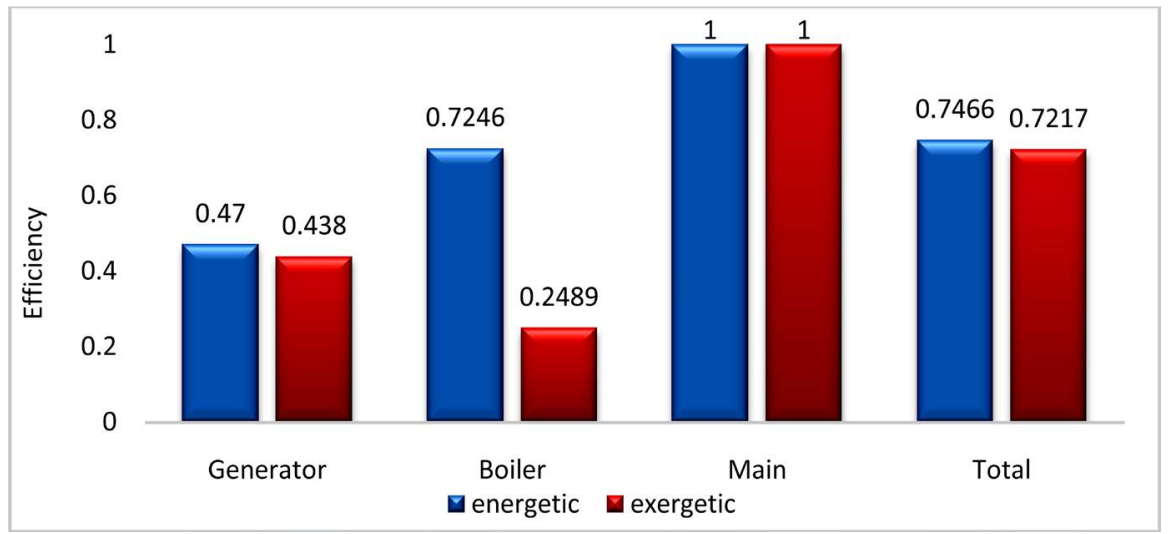

Figure 3. Efficiency of the energy units for the five years' period. 


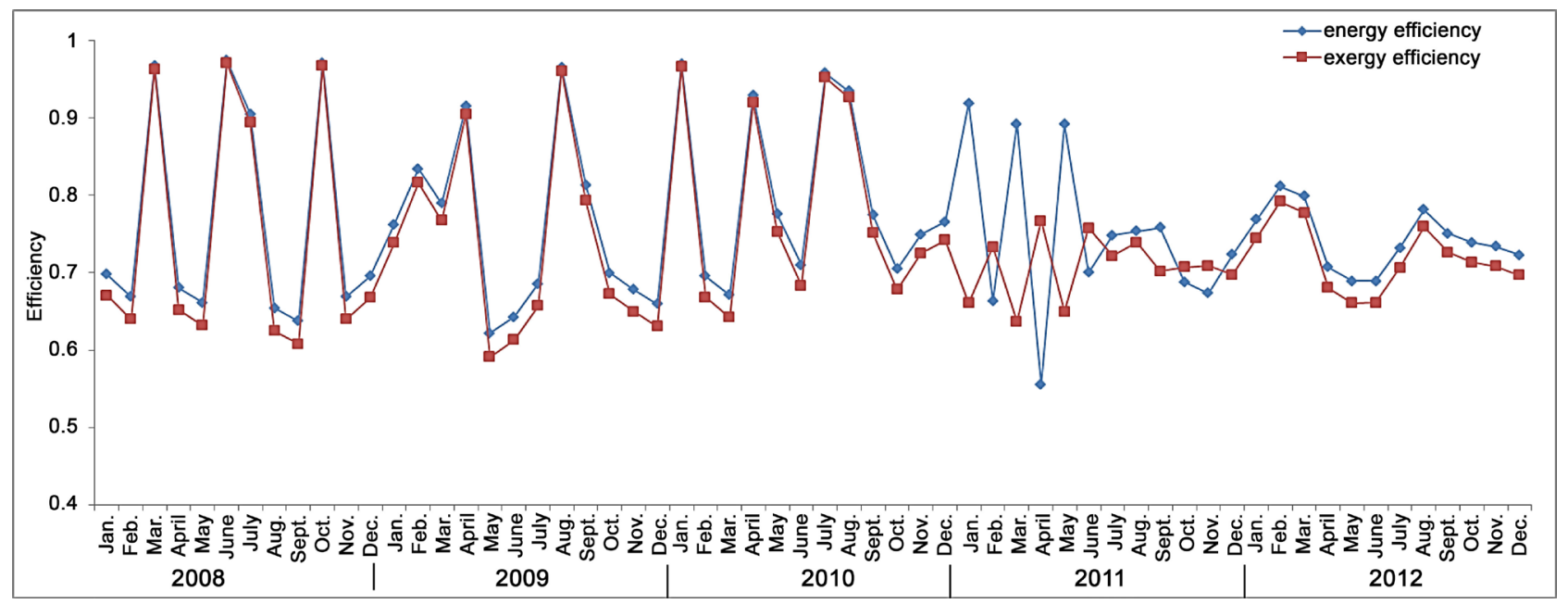

Figure 4. Energetic and exergetic efficiency for five-year duration.

Table 5. Summary of process data analysis.

\begin{tabular}{ccccccccccc}
\hline & $\begin{array}{c}\text { Total Energy } \\
\text { Consumed } \\
(\mathrm{MJ})\end{array}$ & $\begin{array}{c}\text { Energy } \\
\text { Efficiency }\end{array}$ & $\begin{array}{c}\text { Embodied } \\
\text { Energy } \\
\text { Intensity (GJ/t) }\end{array}$ & $\begin{array}{c}\text { Total Exergy } \\
\text { Consumed }\end{array}$ & $\begin{array}{c}\text { Exergy } \\
\text { Efficiency }\end{array}$ & $\begin{array}{c}\text { Process } \\
\text { Efficiency }\end{array}$ & $\begin{array}{c}\text { Pollution } \\
\text { Rate index }\end{array}$ & $\begin{array}{c}\mathrm{CO}_{2} \\
\text { Emission } \\
\times 10^{11}(\mathrm{~g})\end{array}$ & $\begin{array}{c}\text { Energy } \\
\text { Cost/Unit of } \\
\text { Production }\end{array}$ & $\begin{array}{c}\text { Exergy } \\
\text { Cost/Unit } \\
\text { of Prod. }\end{array}$ \\
\hline 2008 & 2.72 & 0.788 & 162.33 & $2,200,793.1$ & 0.613 & 0.613 & 0.6302 & 0.303 & 0.006 & 5479.48 \\
2009 & 4.52 & 0.862 & 139.94 & $3,847,501.3$ & 0.715 & 0.715 & 0.3994 & 0.230 & 0.007 & 4303.84 \\
2010 & 1.27 & 0.624 & 33.97 & $702,782.76$ & 0.324 & 0.324 & 2.0871 & 0.306 & 0.029 & $12,663.58$ \\
2011 & 3.45 & 0.841 & 15.5 & $2,639,591.9$ & 0.621 & 0.621 & 0.6095 & 0.117 & 0.065 & 5267.89 \\
2012 & 4.07 & 0.854 & 2.31 & $3,042,537.2$ & 0.617 & 0.617 & 0.6213 & 0.051 & 0.433 & 5291 \\
Mean & $\mathbf{3 . 2 1}$ & $\mathbf{0 . 7 9 4}$ & $\mathbf{7 0 . 8 1}$ & $\mathbf{2 , 4 8 6 , 6 4 1 . 3}$ & $\mathbf{0 . 5 7 8}$ & $\mathbf{0 . 5 7 8}$ & $\mathbf{0 . 8 6 9 5}$ & $\mathbf{0 . 2 0 2}$ & $\mathbf{0 . 1 0 8}$ & $\mathbf{6 6 0 1 . 1 5 8}$ \\
\hline
\end{tabular}

for $2010,62.13 \%$ for 2011 and $61.68 \%$ for 2012 . With the exception to year 2010, Years 2008, 2009, 2011 and 2012 are all acceptable and the plant was well managed terotechnologically with the process efficiency greater than 50\% [32]. In year 2010, the low process efficiency was attributed to the poor energy mix of 37/63 (Table 4 ) in that year. Generally, the plant is being slightly efficiently run at $57.8 \%$ (mean process efficiency for the five years).

\section{Pollution Rate}

With reference to Table 5, the pollution Rate index estimated for the Aluminium Extrusion plant within the five years' period under review were 0.6302 for 2008; 0.3994 for 2009; 2.0871 for 2010; 0.6095 for 2011 and 0.6213 for 2012. The average pollution Rate index for the Plant within this five year was 0.8695 . Since the mean pollution rate falls in the range $0 \ll R_{\text {poll }} \ll 1$, the plant was negatively impacting the environment due to technological limitation of the energy conversion process employed in the manufacturing plant [29].

Figure 5 above shows that increase in process efficiency results in low pollution rate. The high pollution rate in 2010 was as a result of poor energy mix 37/63 instead of the recommended 70/30. 


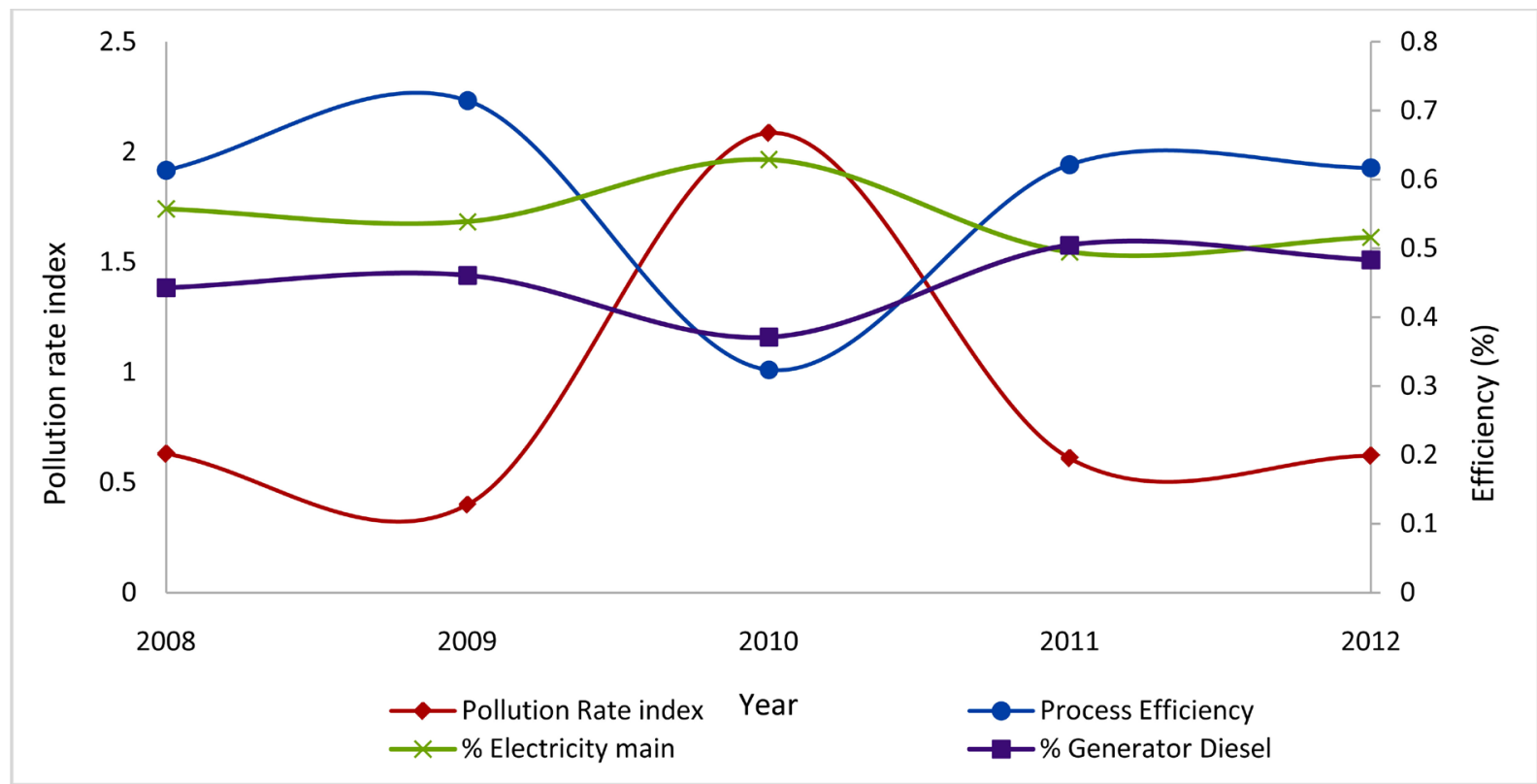

Figure 5. Relationship between pollution rate, energy mix and process efficiency.

\section{Embodied Energy Intensity}

The estimated values of the Embodied Energy Intensity for the five years under review are shown in Table 5. The Embodied Energy Intensity for the five years under review (2008-2012) are very high (2.31 - 162.3 GJ/t) when compared with the global best practices which recommended an Embodied Energy Intensity Utilization in the range $2.9-3.2 \mathrm{GJ} / \mathrm{t}$ [33]. This accounted for high cost of production of the goods and hence the sales price of the products, among other parameters that are used in price determination. The mean value of $70.81 \mathrm{GJ} / \mathrm{t}$ is well outside the acceptable range, this is attributed to the total Energy used and the Exergy supply mix in-balance.

\section{Carbon IV Oxide Emission}

The Green House Gas (GHG) estimated for the five years in this manufacturing plant is carbon IV oxide $\left(\mathrm{CO}_{2}\right)$. The total $\mathrm{CO}_{2}$ emission for the five-year period was $0.1007 \mathrm{Mt}$ with an average of $0.0202 \mathrm{Mt}$ of $\mathrm{CO}_{2}$ annually with the environment.

As shown in Figure 6, the worst year of this GHG emission for this particular industry was 2010 and 2008, even though this was not the year with the highest total energy application and the least quantity was emitted in the year 2010 despite the fact that these was not the year with the least total energy usage. However, this is explainable by the energy supply mix for these years; it was observed that the energy balance ratio deviated significantly from the recommended 70/30.

Economic Analysis of Energy Usage in the Manufacturing Plant

The mean annual overall energy unit cost and the mean overall exergy unit cost for this manufacturing plant are shown in Figure 7. Comparing this trend of overall energy and exergy unit cost with the trend of energy and exergy efficiency, it shows that the highest mean annual overall energy unit cost of production ( 


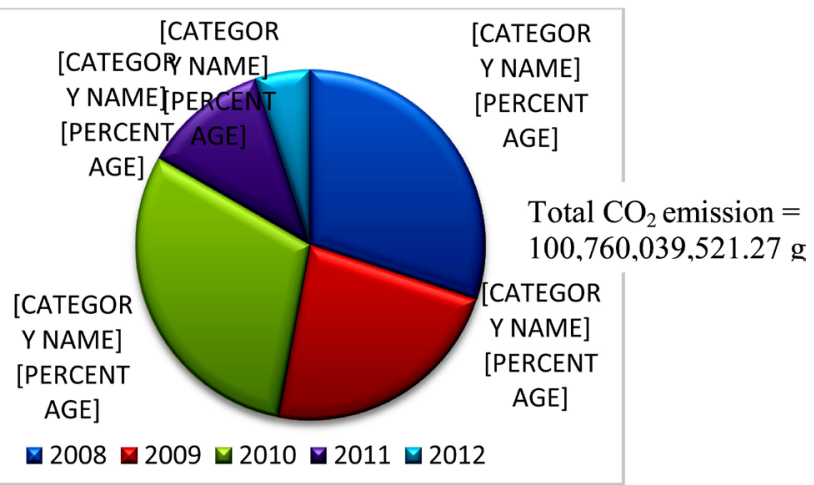

Figure 6. $\mathrm{CO}_{2}$ emission for the year.

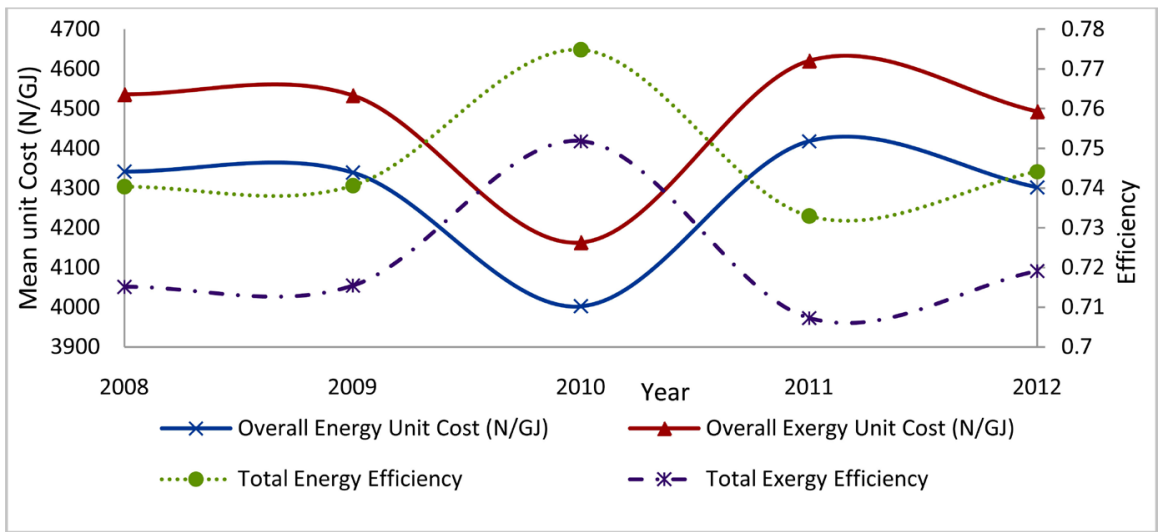

Figure 7. The mean unit exergy and energy cost with efficiencies.

4418.311/GJ) corresponds to the minimum energy efficient (73.3\%) in year 2011 in this industry. Furthermore, the minimum exergy efficient (70.73\%) in year 2011 corresponds to the maximum mean annual overall exergy unit cost ( 4620.372/GJ).

Further observation of the trends of these parameters reveals that there is an inverse relationship between the energy/exergy efficiency and the overall energy/ exergy unit cost of production as shown in Figure 7.

\section{Conclusions}

The energy and production data of the aluminium extrusion plant was analysed for energy and exergy utilisation, greenhouse emission and economy of energy usage. It can be concluded that:

The company energy mix is disproportionate to the best practices. The plant is run averagely efficiently with the majority of exergetic losses occurring in the boiler. The pollution rate index is high and it is due to the energy conversion methods. The high greenhouse emission from the plant is also as a result of poor energy mix. The high cost of production is attributable to the poor energy and exergy supply mix.

In other word, to improve the process efficiency, an improvement technology should be applied in the manufacturing process. The energy mix of 70/30 should be adhered to economic, efficient and environmental friendly operation. 


\section{References}

[1] Jinadu, J.A. (2005) Evaluation of Energy Utilization in a Private Company. Unpublished PGD Project Work. Federal University of Technology, Akure.

[2] Arif, I. and Turker, G. (1998) Energy and Exergy Utilization in Turkey during 1995. Energy, 23, 1099. https://doi.org/10.1016/S0360-5442(98)00063-2

[3] Aiyedun, O.O. and Onakoya, B.A. (2002) Energy Efficiency of a Private Sector Production Company. Nigeria Journal of Industrial and System Studies, 1, 15-24.

[4] EIA (2008) USA Energy Department, Annual Energy Review 2008. https://www.eia.org

[5] Adedeji, W.O. and Badmus, I. (2012) Energy and Economic Analysis of Energy Sourcing Pattern in a Nigerian Brewery. International Journal of Scientific and Engineering Research, 3, 2229-5518.

[6] Dincer, I. and Rosen, M.A. (2007) Exergy, Energy, Environment and Sustainable Development (Chapter 4: Thermodynamic Fundamentals). Elsevier Science, Amsterdam, 1-21.

[7] Reistad, G.M. (1975) Available Energy Conversion and Utilisation in the United State. Journal of Engineering Power, 97, 429-434. https://doi.org/10.1115/1.3446026

[8] Rosen, M.A. (1992) Evaluation of Energy Utilisation Efficiency in Canada Using Energy and Exergy Analysis. Energy-The International Journal, 17, 339-350. https://doi.org/10.1016/0360-5442(92)90109-D

[9] Wall, G. (1988) Exergy Flows through Industrial Process. Exergy, 13, 199-214.

[10] Wall, G. (1990) Exergy Conversion in Japanese Society. Exergy, 15, 435-444. https://doi.org/10.1016/0360-5442(90)90040-9

[11] Wall, G. (1991) Exergy Conversion in the Finnish, Syracuse and Swedish Societies. OPUSCULA Exergy Progress, 15, 1-11.

[12] Ozdogan, O. and Arkel, M. (1995) Energy and Exergy Analysis of Selected Turkish Industries. Exergy, 20, 73-80.

[13] Rosen, M.A. and Dincer, I. (1999) Thermal Storage and Exergy Analysis: The Impact of Stratification. Transactions of the CSME 23 (IB), 73-186.

[14] Vyzinkarova, D., Allegrini, E, Laner, D. and Astrup, T.F. (2013) Exergy Analysis of Aluminum Recovery from Municipal Solid Waste Incineration. Proceeding of $3 \mathrm{rd}$ International Exergy, Life Cycle Assessment, and Sustainability Workshop \& Symposium (ELCAS3), Nisyros, 459-457.

[15] Rosen, M.A. and Lee, D.L. (2009) Exergy-based Analysis and Efficiency Evaluation for an Aluminium Melting Furnace in a Die-casting Plant. Proceedings of the 4 th IASME/ WSEAS International Conference on Energy \& Environment, Cambridge, 24-26 February 2009, 160-165.

[16] Acevedo, L., Usón, S. and Uche, J. (2015) Exergy Transfer Analysis of an Aluminium Holding Furnace. Energy Conversion and Management, 89, 484-496. https://doi.org/10.1016/j.enconman.2014.10.021

[17] Oladiran, M. and Meyer, J.P. (2007) Energy and Exergy Analysis of Energy Consumptions in the Industrial Sector in South Africa. Applied Energy, 84, 1056-1067. https://doi.org/10.1016/j.apenergy.2007.02.004

[18] Diji, C.J. (2007) Energy-Exergy Analysis and Carbon (IV) Oxide Emission Estimation of the Cement Manufacturing Industry in Nigeria. PhD Thesis, University of Ibadan.

[19] Waheed, M., Jekayinfa, S., Ojediran, J. and Imeokparia, O. (2008) Energetic Analy- 
sis of Fruit Juice Processing Operations in Nigeria. Energy, 33, 35-45. https://doi.org/10.1016/j.energy.2007.09.001

[20] Badmus, I. and Osunleke, A.S. (2010) Application of Energy and Exergy Analysis for Efficient Energy Utilization in the Nigerian Residential Sector. International Journal of Exergy, 7, 352-368. https://doi.org/10.1504/IJEX.2010.031989

[21] Fadare, D.A., Nkpeube, D.O., Oni, F.A., Waheed, M.A. and Bamiro, O.A. (2010) Energy and Exergy Analyses of Malt Drink Production in Nigeria. Energy, 35, 533-646.

[22] Badmus, I. and Shokunbi, M.O. (2012) Energy, Energy and Economic Analyses of Energy Sourcing Pattern in a Lagos-Based Milk Producing Company. International Journal of Pure and Applied Sciences and Technology, 11, 67-78.

[23] Adedeji, W.O. and Badmus, I. (2012) Energy Exergy and Economic Analysis of Energy Sourcing Pattern: In A Nigerian Brewery. Energy and Power Engineering, 4, 404-414. https://doi.org/10.4236/epe.2012.46054

[24] Adedeji, W.O. (2015) Energy-Exergy Analysis and Carbon (IV) Oxide Emission Estimation of Selected Food and Beverage Manufacturing Companies in Lagos, Nigeria. A Doctoral Thesis, Federal University of Technology, Abeokuta.

[25] Costal, M.M., Schaeffer, R. and Worrel, E. (2001) Exergy Accounting of Energy and Materials Flows in Steel Production Systems. Energy, 26, 363-384. https://doi.org/10.1016/S0360-5442(01)00004-4

[26] Jaber, J.O., Al-Ghandoor, A. and Sawalha, S.A. (2008) Energy and Exergy Utilisation in the Transportation Sector of Jordan. Energy Policy, 36, 2995-3000. https://doi.org/10.1016/j.enpol.2008.04.004

[27] Tsatsaronis, G. and Cziesta, F. (2003) Thermodynamics. Summer Course on Optimisation of Energy Systems and Processes, Gliwice.

[28] Hepbasli, A. (2008) A Study on Estimating the Energetic and Exergetic Prices of Various Residential Energy Sources. Energy \& Buildings, 40, 308-315. https://doi.org/10.1016/j.enbuild.2007.01.023

[29] Makarytchev, S.V. (1997) Environmental Impact Analysis of ACFB-Based Gas and Power Cogeneration. Energy, 23, 711-717. https://doi.org/10.1016/S0360-5442(98)00017-6

[30] Intergovernmental Panel on Climate Control (1996) Revised IPCC Guidelines or National Greenhouse Gas Inventories: Reference Manual.

[31] ECN (2012) National Energy Policy. The Presidency, Energy Commission of Nigeria. http://www.energywatchgroup.org

[32] Koroneos, C., Roumbas, G. and Moussiopoulos, N. (2005) Exergy Analysis of Cement Production. International Journal of Energy, 2, 55-68. https://doi.org/10.1504/IJEX.2005.006433

[33] Worrel, E., Levine, M.D., Price, L.K., Martins, N.C., Vanden, B.R. and Blok, K. (1997) Potential and Policy Implication of Energy and Material Efficiency Improvement. Commission for Sustainable Development, New York. 